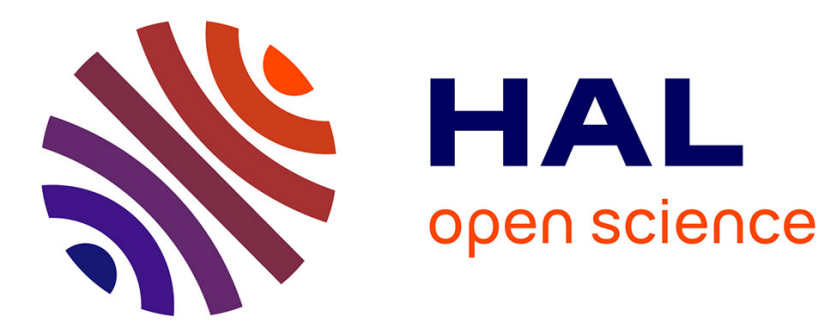

\title{
1-Hydroxypyrene as a biomarker of PAH exposure in the marine polychaete
}

Zhanna M. Tairova, Anders M.B. Giessing, Rikke Hansen, Ole Andersen

\section{To cite this version:}

Zhanna M. Tairova, Anders M.B. Giessing, Rikke Hansen, Ole Andersen. 1-Hydroxypyrene as a biomarker of PAH exposure in the marine polychaete. Marine Environmental Research, 2008, 67 (1), pp.38. 10.1016/j.marenvres.2008.10.005 . hal-00501982

\section{HAL Id: hal-00501982 \\ https://hal.science/hal-00501982}

Submitted on 13 Jul 2010

HAL is a multi-disciplinary open access archive for the deposit and dissemination of scientific research documents, whether they are published or not. The documents may come from teaching and research institutions in France or abroad, or from public or private research centers.
L'archive ouverte pluridisciplinaire HAL, est destinée au dépôt et à la diffusion de documents scientifiques de niveau recherche, publiés ou non, émanant des établissements d'enseignement et de recherche français ou étrangers, des laboratoires publics ou privés. 


\section{Accepted Manuscript}

1-Hydroxypyrene as a biomarker of PAH exposure in the marine polychaete Nereis diversicolor

Zhanna M. Tairova, Anders M.B. Giessing, Rikke Hansen, Ole Andersen

PII:

S0141-1136(08)00221-3

DOI:

10.1016/j.marenvres.2008.10.005

Reference:

MERE 3297

To appear in:

Marine Environmental Research

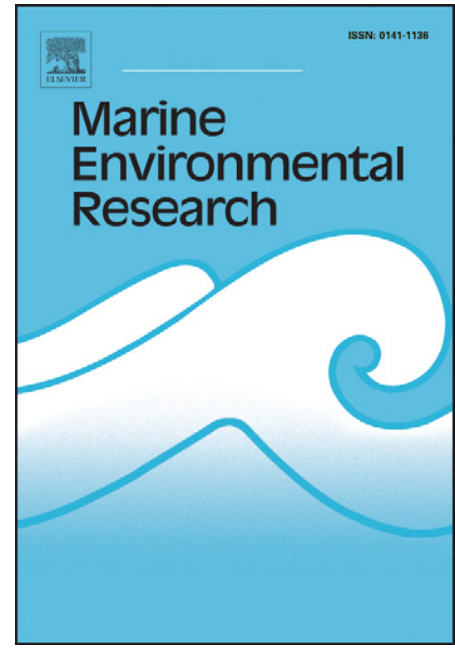

Received Date: $\quad 22$ March 2008

Revised Date: $\quad 8$ October 2008

Accepted Date: $\quad 16$ October 2008

Please cite this article as: Tairova, Z.M., Giessing, A.M.B., Hansen, R., Andersen, O., 1-Hydroxypyrene as a biomarker of PAH exposure in the marine polychaete Nereis diversicolor, Marine Environmental Research (2008), doi: 10.1016/j.marenvres.2008.10.005

This is a PDF file of an unedited manuscript that has been accepted for publication. As a service to our customers we are providing this early version of the manuscript. The manuscript will undergo copyediting, typesetting, and review of the resulting proof before it is published in its final form. Please note that during the production process errors may be discovered which could affect the content, and all legal disclaimers that apply to the journal pertain. 


\title{
1-Hydroxypyrene as a biomarker of $\mathrm{PAH}$ exposure in the marine polychaete Nereis diversicolor
}

\author{
Zhanna M. Tairova ${ }^{\mathrm{a}^{*}}$, Anders M.B. Giessing ${ }^{\mathrm{b}}$, Rikke Hansen ${ }^{\mathrm{c}}$, Ole Andersen ${ }^{\mathrm{a}}$ \\ ${ }^{a}$ Department of Science, Systems and Models, Roskilde University, Universitetsvej 1, DK-4000 Roskilde, Denmark \\ ${ }^{\mathrm{b}}$ Protein Research Group, Department of Biochemistry and Molecular Biology, University of Southern Denmark, \\ Campusvej 55, DK-5230 Odense M, Denmark \\ ${ }^{c}$ Grontmij - Carl Bro, Granskoven 8, DK-2600, Glostrup, Denmark.
}

\begin{abstract}
The possibility of using the pyrene metabolite 1-hydroxypyrene as a biomarker of polycyclic aromatic hydrocarbons (PAH) exposure was investigated by exposure of the marine polychaete Nereis diversicolor to several PAHs in the laboratory. Animals were exposed to pyrene alone and to five different PAHs - phenanthrene, anthracene, pyrene, benzo[a]pyrene and benzo[k]flouranthene. After 5 days of exposure the concentrations of parent PAHs and 1hydroxypyrene were identified using three different analytical methods, high-performance liquid chromatography with fluorescence detection (HPLC/F), synchronous fluorescence spectroscopy (SFS) and gas chromatography with mass spectrometric detection (GC/MS). The SFS measurements of 1-hydroxypyrene were validated by the more sensitive method HPLC/F. The positive correlation between total PAHs and 1-hydroxypyrene concentrations in the polychaete tissues observed in experiments, suggests the feasibility of 1-hydroxypyrene as a suitable biomarker for total PAH exposure assessment. Furthermore, the possibility of employment of the simple and rapid SFS method instead of HPLC/F for biomarker analysis has been confirmed by the positive and significant correlation between results achieved by these two analytical methods.
\end{abstract}

Keywords: 1-Hydroxypyrene; Nereis diversicolor; Biomarker; Polychaete; PAH; HPLC; SFS; Sediment pollution.

\section{Introduction}

Environmental contamination with polycyclic aromatic hydrocarbons (PAHs) is a matter of concern, as this contamination is widespread in both marine and terrestrial environments and some PAHs are carcinogenic (Neff, 1985; Ariese et al., 1993; Giessing et al., 2003a). PAH pollution originates from both natural and anthropogenic sources, the latter being the major contributor (Levin, 1995). Being natural components of fossil fuels, PAHs are emitted to the environment due to incomplete combustion and as a result of crude oil spillages (Walker et al., 2001). Generally, environmental exposure of organisms to PAHs is assessed by monitoring their environment (sediment/soil, water, and air), and routine monitoring of contaminants levels in the aquatic environment usually involves determination of parent $\mathrm{PAH}$ in sediment and animal tissue samples (Ariese et al., 1993; Fillmann et al., 2004). However, chemical analysis of these samples provides little useful information for compounds that are readily metabolized and, therefore, biomonitoring of PAH exposure should include determination of PAH metabolites in animal tissues.

Pyrene is a constituent of all environmental mixtures of PAH (Levin, 1995; Jongeneelen et al., 1985). Pyrene is not particularly toxic and only one phase I metabolite, 1-hydroxypyrene, is formed by biotransformation process in eukaryotic organisms (Giessing et al., 2003a). As this is an extensive analytical advantage, pyrene is a widely used model compound in studies of PAH

\footnotetext{
* Corresponding author. Address: Department of Science, Systems and Models, Roskilde University, Universitetsvej 1, DK-4000 Roskilde, Denmark. Tel.: +45 30229901; Fax: +4546743011. E-mail address: zhanna@ ruc.dk.
} 
metabolism (Giessing et al., 2003a). Being a major metabolite of a representative compound in PAH mixtures, 1-hydroxypyrene can be used as a biomarker of total PAH exposure (Levin, 1995).

1-Hydroxypyrene was introduced as a biomarker of human occupational PAH exposure by Jongeneelen et al. (Jongeneelen et al., 1985). Its applicability as a biomarker in humans has been tested and verified in hundreds of studies (Levin, 1995, Jongeneelen et al., 1987; Jongeneelen et al., 1988; Goen et al., 1995; Boogaard and Vansittert, 1995; Tsai et al., 2002; Tsai et al., 2004; Levin et al., 1995; Strickland and Kang, 1999; Viau et al., 1995; Viau and Vyskocil, 1995). Based on a robust and non-laborious analytical method urinary 1-hydroxypyrene is a useful biomarker of human PAH exposure (Jongeneelen et al., 2001). In fish, PAH exposure can be assessed by screening the gall bladder bile for 1-hydroxypyrene (Ariese et al., 1993; Aas et al, 1998). Also in several invertebrate species, e.g. Dungeness crab and the terrestrial isopod Porcellio scaber, 1hydroxypyrene has been used as a suitable indicator for PAH exposure (Eickhoff et al, 2003; Stroomberg et al., 1999). In the present study we extend the use of 1-hydroxypyrene as biomarker of environmental PAH exposure to marine sediments, by use of the sessile infaunal invertebrate species of marine polychaete Nereis diversicolor.

Analytical methods for identification and quantification of PAHs and their metabolites usually involve chromatographic separation by high-performance liquid chromatography (HPLC) or gas chromatography (GC) with mass spectrometric or fluorescence detection (Ariese et al., 1993; Lin et al., 1994). The total analysis time using these methods is considerable in comparison to fluorescence spectroscopy methods. Environmental monitoring often requires screening large numbers of samples and, therefore, it is desirable to use a simpler, less expensive and time consuming method to assess PAH exposure than, for example, gas chromatography with mass spectrometric detection GC/MS or high-performance liquid chromatography with fluorescence detection HPLC/F (Ariese et al., 1993; Lin et al., 1994). However, more rapid alternative analytical methods for biomonitoring must be just as sensitive and specific for PAHs as chromatographic methods.

Conventional fluorescence spectroscopy has an excellent sensitivity in determining trace organic compounds but its application to simultaneous determination of several fluorescent compounds in mixtures is limited due to spectral overlap for compounds with high structural similarity (Rodriquez and Sanz, 2000), as is the case for pyrene and 1-hydroxypyrene. Such spectral interferences can, sometimes, be resolved by synchronous fluorescence spectroscopy (SFS), i.e. by scanning both the excitation and emission simultaneously with a constant wavelength difference (Eickhoff et al, 2003; Lin et al., 1994; Giessing et al., 2003b). In recent years, SFS has been used increasingly to screen for pyrene metabolites in various matrices including human urine (Strickland et al., 1994), fish bile (Ariese et al., 1993; Lin et al., 1994), and crab hemolymph and urine (Eickhoff et al, 2003; Watson et al., 2004). Giessing et al. (2003) showed the usefulness of 1-hydroxypyrene measured by SFS as a biomarker for pyrene exposure in Nereis diversicolor, demonstrating a good correlation between SFS and HPLC with ultraviolet detection (HPLC/UV) measurements of 1-hydroxypyrene (Giessing et al., 2003b). In the present study the formation of pyrene metabolites in the marine polychaete Nereis diversicolor was investigated, with special attention given to the detection of 1-hydroxypyrene using SFS. HPLC/F and GC/MS were used as complementary methods for confirmation of the SFS results.

To evaluate the feasibility of 1-hydroxypyrene as biomarker for assessing environmental exposure to PAHs, the correlation between 1-hydroxypyrene and total PAH content in animal tissues and sediment was investigated in experiments, where Nereis diversicolor was exposed to mixture of different PAHs. Accordingly, the objectives of this study were to evaluate the feasibility of (i) 1-hydroxypyrene in polychaete worms as a biomarker for assessing total PAH exposure, and (ii) a rapid SFS method for identification and quantification of 1-hydroxypyrene.

\section{Materials and Methods}




\subsection{Chemicals}

Pyrene (98\%) and 1-hydroxypyrene (98\%) were purchased from Sigma Aldrich (Germany). EPA Polynuclear Aromatic Hydrocarbons Kit 610 - N (phenanthrene (99,9\%), anthracene (99,1\%), pyrene (98\%), benzo[a]pyrene (96,9\%) and benzo[k]flouranthene (99,7\%)); EPA 610 Polynuclear Aromatic Hydrocarbons Mix, solution in methanol:methylene chloride (1:1); Quebec Ministry of Environment PAH MIX in methylene chloride:benzene (75:25), were purchased from Supelco (USA). HPLC grade acetone, acetonitrile, methanol were acquired from Lab Scan (Dublin, Ireland). Ethanol (96\%) from De Danske Spritfabrikker A/S (Denmark). Enzyme $\beta$-glucuronidasearylsulfatase (from Helix pomatia, 108,750 U/ml, and 134,3 U/ml) was supplied by Sigma Aldrich (Germany). Ammonium acetate and Acetic acid (100\%) were from Merck (Germany). All chemicals were used as received.

\subsection{Laboratory studies}

2.2.1 Test animals. Individual Nereis diversicolor were collected on a sand flat at Store Havelse, Roskilde Fjord, Denmark. Worms were sorted according to size and physical condition in order to use a homogeneous collection of animals for experiments. Animals were kept in culture in native sediment with seawater $(16 \%$ ) from the fjord for a minimum of 7 days prior to use.

2.2.2 Sediment spiking. Sediment collected at the same time as worms was sieved $(1 \mathrm{~mm})$ and frozen $\left(-18^{\circ} \mathrm{C}\right)$ until use. Thawed sediment was contaminated by adding the desired amounts of PAHs dissolved in a minimum amount of acetone to sediment slurry and $0.45 \mu \mathrm{m}$ filtered seawater. This slurry was mixed continuously with a pillar drilling machine for approximately 12 hours. After settling, overlying water was decanted, and the sediment was kept at $4^{\circ} \mathrm{C}$ for 1 week prior to use in microcosms. In this way sediments with different concentrations of pyrene (pyrene exposure experiment) or of a mixture of 5 PAHs - phenanthrene, anthracene, pyrene, benzo[a]pyrene $(\mathrm{B}[\mathrm{a}] \mathrm{p})$ and benzo[k]flouranthene $(\mathrm{B}[\mathrm{k}] \mathrm{f})$ (five PAHs experiment) were produced.

2.2.3 Concentration-response relationship experiments with pyrene. Three independent replicates in plastic containers with $200 \mathrm{ml}$ of sediment and 200-300 ml of overlying filtered seawater water $\left(16 \%\right.$ ) were established at 1,10 and $30 \mathrm{mg}$ pyrene $\mathrm{kg}^{-1}$ sediment (dw). Each container was continuously aerated throughout the experiment. Individuals of Nereis diversicolor were added (1 worm per container). After 5 days of exposure whole worms were collected and treated as described below. Pyrene and 1-hydroxypyrene were identified and quantified using HPLC/F and SFS.

2.2.4 Five PAHs exposure experiment. Three independent replicates in plastic containers with 200 $\mathrm{ml}$ of sediment and $400 \mathrm{ml}$ of overlying filtered seawater (16\%o) were established at nominal concentrations: $2.5,10$ and $50 \mathrm{mg}$ of total PAH kg${ }^{-1}$ sediment (dw). The total PAH concentration is the sum of the concentrations of all five compounds: phenanthrene, anthracene, pyrene, $\mathrm{B}[\mathrm{a}] \mathrm{p}$, $\mathrm{B}[\mathrm{k}] \mathrm{f}$, in equal weight proportions. Each container for the exposure concentrations 2.5 and $10 \mathrm{mg}$ $\mathrm{kg}^{-1}$ sediment (dw) - contained five worms, while the concentration $50 \mathrm{mg} \mathrm{kg}^{-1}$ sediment (dw) and control treatments contained one worm in each replicate. Each container was continuously aerated throughout the experiment. After 5 days of exposure whole worms were collected and treated as described below. Phenanthrene, anthracene, pyrene, $b[a] p$ and $b[k] f$ were identified and quantified using HPLC/F. The amount of 1-hydroxypyrene was measured using HPLC/F and SFS.

\subsection{Sample treatment}

Worms were collected after 5 days of exposure and allowed to defecate in individual aluminum dishes containing overlying water from the experimental container. After four hours most of the worms had purged their guts of the sediment (visual observation). The worms were weighed (ww) 
and transferred to test tubes containing $2 \mathrm{ml}$ of methanol and, subsequently, homogenized using a Tissue Tearor (Biospec Products, Inc. Bartesville, OK, USA) at full speed for $1 \mathrm{~min}$. Samples were then sonicated for $10 \mathrm{~min}$ and, subsequently, centrifuged at $1239 \mathrm{~g}$ for $10 \mathrm{~min}$ to precipitate debris. The supernatant was collected and filtered through a $0.22 \mu \mathrm{m}$ syringe filter and transferred directly to brown HPLC vials without any further sample preparation for the pyrene single exposure experiment. For the five PAHs experiment, samples from the two lowest exposure concentrations were pooled in the following way: five animals from the same container were extracted separately in methanol. Upon centrifugation, supernatants were pooled into one vial. Pooled samples were then evaporated to dryness under a gentle flow of nitrogen and re-diluted in $2 \mathrm{ml}$ of methanol. All samples were stored at $-80^{\circ} \mathrm{C}$ prior to further treatments.

2.3.1 Enzymatic hydrolysis. Glucuronidase-arylsulfatase enzymes hydrolyze glucuronide and sulfate conjugates to give free 1-hydroxypyrene (Giessing et al., 2003b). To achieve maximum enzymatic hydrolysis and get an amount of 1-hydroxypyrene per sample sufficient for SFS analysis, the concentration of tissue extracts in methanol, amount of enzyme units, and time of incubation at $37^{\circ} \mathrm{C}$ were optimized. The enzyme activity is inhibited by the presence of methanol in the extracts. Thus, since the amount of the sample incubated with enzyme was relatively high (up to 1:10 final dilution) we added more enzyme and applied longer incubation period than previously described (Giessing et al., 2003b).

Tissue methanol extracts from the pyrene exposure experiment were diluted 1:3 in ammonium acetate buffer $(\mathrm{pH}=5)$ and diluted $1: 150$ with $0.22 \mu \mathrm{m}$ filtered deionized water (DI) and incubated for $18 \mathrm{hrs}$ at $37^{\circ} \mathrm{C}$ with approximately 100 units of $\beta$-glucuronidase-arylsulfatase. After addition of $500 \mu \mathrm{l}$ of ice-cold $99.9 \%$ ethanol, samples were mixed and centrifuged at $3000 \mathrm{~g}$ for 5 $\min$ at $4^{\circ} \mathrm{C}$ to precipitate denatured protein.

Tissue methanol extracts from the five PAHs experiment were diluted 1:25 with $0.22 \mu \mathrm{m}$ filtered DI and incubated for $22 \mathrm{hrs}$ at $37^{\circ} \mathrm{C}$ with approximately 100 units of $\beta$-glucuronidasearylsulfatase. After addition of $500 \mu \mathrm{l}$ of ice-cold $99.9 \%$ ethanol, samples were mixed and centrifuged at $3000 \mathrm{~g}$ for $5 \mathrm{~min}$ at $4^{\circ} \mathrm{C}$ to precipitate denatured protein.

The supernatant from both treatments was transferred to brown HPLC vials and analyzed using HPLC/F and SFS.

2.3.2 Synchronous fluorescence spectroscopy. Samples from enzymatic hydrolysis were analyzed by SFS (Perkin Elmer Luminiscence spectrometer LS50B) without further treatment, using a 5 $\mathrm{mm}$ quartz cuvette. The spectroscopic conditions were set as $5 \mathrm{~nm}$ slits on excitation and emission channels and photomultiplier tube (PMT) voltage of $900 \mathrm{~V}$, using a scan speed of $1200 \mathrm{~nm} / \mathrm{min}$, and scanning the wavelength range $250-400 \mathrm{~nm}$ with a constant wavelength difference of $34 \mathrm{~nm}$ between excitation and emission channels. Calibration curves were made by preparing standard dilutions of 1-hydroxypyrene in methanol added into a tissue matrix from extracts of unexposed worms. For the analysis of samples from the pyrene single exposure experiment, the standard dilutions of 1-hydroxypyrene were added into tissue matrix without treating it with enzyme. For the quantitative analysis of samples from the five PAHs exposure experiment, standard dilutions of 1-hydroxypyrene were added into matrix, tissue of unexposed worm, which had undergone the same treatment with enzyme as the analytes. Calibration curves had regression coefficients $r^{2}>$ 0.98 in both cases.

2.3.3 High performance liquid chromatography. Quantification of metabolites and parent PAHs was done by HPLC/F. The system consisted of a Dionex P680 HPLC Pump (2002 Dionex, Version 1.0), an automated Sample Injector ASI-100 (2001 Dionex Softron GmbH, Version 1.14), a column oven STH585 (2000 Dionex Softron GmbH, Version 2.50) and a Dionex RF2000 Flourescence Detector (2000 Dionex Softron GmbH, Version 1.40). 
Quantification of pyrene and 1-hydroxypyrene in tissue samples from Nereis diversicolor was done using a Phenomenex Synergi 4u Hydro-RP 80A C18 column, $15 \mathrm{~cm}$ x $4.6 \mathrm{~mm}$ (Phenomenex, USA). The acetonitrile/water gradient profile was 50:50 for $5 \mathrm{~min}, 100: 0$ over 10 min, held for $5 \mathrm{~min}$, and finally 50:50 over $5 \mathrm{~min}$ at a flow rate of $1 \mathrm{ml} \mathrm{min}{ }^{-1}$. Column temperature was kept at $28^{\circ} \mathrm{C}$. The excitation and emission wavelengths of the fluorescence detector were set at $346 \mathrm{~nm}$ and $384 \mathrm{~nm}$, respectively. The excitation wavelength was changed to $333 \mathrm{~nm}$ after 14 min. Spectral bandwidths of the fluorescence detector were always fixed at $15 \mathrm{~nm}$ for both, excitation and emission.

Identification of conjugated metabolites and 1-hydroxypyrene in tissues of Nereis diversicolor prior to enzymatic treatment was performed using a reversed phase Phenomenex Synergi 4u Fusion-RP 80A C18 column, $25 \mathrm{~cm} \mathrm{x} 4.6 \mathrm{~mm}$ (Phenomenex, USA). The acetonitrile/buffer $(10 \mathrm{mM}$ ammonium acetate buffer, $\mathrm{pH}=5)$ gradient profile used for the quantification of conjugated metabolites and 1-hydroxypyrene was 5:95 for $2 \mathrm{~min}$, the proportion of acetonitrile increased linearly over $35 \mathrm{~min}$ to 90:10, held for $13 \mathrm{~min}$, and decreased to 5:95 over

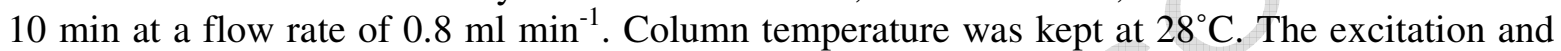
emission wavelengths of the fluorescence detector were set at $346 \mathrm{~nm}$ and $384 \mathrm{~nm}$, respectively, to measure metabolites, and then the excitation wavelength was changed to $333 \mathrm{~nm}$ after $37 \mathrm{~min}$, to measure the parent compound.

Quantification of phenanthrene, anthracene, pyrene, benzo[a]pyrene and benzo[k]fluoranthene was carried out, using a Primshere C18 column $(25 \mathrm{~cm} \mathrm{x} 4.6 \mathrm{~mm}$, Phenomenex, Torrance, CA, USA). The acetonitrile/water gradient was 40:60 for $2 \mathrm{~min}$, then increased at a linear rate to 100:0 over $20 \mathrm{~min}$, held for $8 \mathrm{~min}$, and changed back to 40:60 over 2 min, at a flow rate of $1.5 \mathrm{ml} \mathrm{min}^{-1}$. The column temperature was kept at $30^{\circ} \mathrm{C}$. The excitation and emission wavelengths of the fluorescence detector were set at $254 \mathrm{~nm}$ and $395 \mathrm{~nm}$, respectively. During the run, the excitation/emission wavelengths were changed twice: to $335 \mathrm{~nm} / 380 \mathrm{~nm}$ after $19 \mathrm{~min}$ and to $290 \mathrm{~nm} / 420 \mathrm{~nm}$ after $22 \mathrm{~min}$.

The identification and quantification of 1-hydroxypyrene and parent PAHs was performed using external standard dilutions of these compounds in methanol.

2.3.4 Tissue samples for GC/MS analysis. Tissue extracts for total PAH content analysis by GC/MS were prepared in two steps. The first extraction step was with methanol as previously described for HPLC/F analysis. After removing the methanol phase, tissues were re-extracted in dichloromethane (DCM) to extract residual PAH from animal tissues. $2 \mathrm{ml}$ of DCM were added and the procedure was then as described for methanol extraction. The DCM phase of tissue extracts was collected upon centrifugation and samples were dried using $\mathrm{Na}_{2} \mathrm{SO}_{4}$ containing glass pipettes. Aliquots were evaporated down to $1 \mathrm{ml}$ under a gentle flow of nitrogen, prior to analysis on GC/MS.

2.3.5 Sediment samples GC/MS analysis. Wet sediment samples collected at the end of the experiment were extracted in $30 \mathrm{ml}$ of DCM in a Microwave Accelerated Reaction System (Model MARS 5®; CEM Corporation) by ramping for $10 \mathrm{~min}$. to reach $110^{\circ} \mathrm{C}$ and then holding for $25 \mathrm{~min}$ at this temperature. Cooled samples were dried using $\mathrm{Na}_{2} \mathrm{SO}_{4}$ and cleaned of organic debris using columns filled with activated Silica gel and $\mathrm{Na}_{2} \mathrm{SO}_{4}$. Columns were eluted with $40 \mathrm{ml}$ DCM and extracts were evaporated to lower their volume under a gentle flow of nitrogen. Extracts were dried again using $\mathrm{Na}_{2} \mathrm{SO}_{4}$ prior to GC/MS analysis. Internal and recovery standards, both containing deuterated PAHs, were added to the extracts at the beginning and at the end of the extraction procedure, respectively. External calibration curves were used for the quantification analysis of each of the PAHs. All calibration curves had regression coefficients $r^{2}>0.98$. 
2.3.6 Gas chromatography mass spectrometry. Gas chromatography mass spectrometric (GC/MS) analysis of sediment and tissue samples from the five PAHs experiment was performed on a Finnigan TRACE DSQ ${ }^{\mathrm{TM}}$ Single Quadrupole GC-MS (Thermo Electron Corporation) with a $60 \mathrm{~m}$ HP-5MS capillary column (0.25 mm i.d. x $0.25 \mathrm{um}$ film) and operated in electron ionisation (EI) mode. The injection volume was $1 \mu \mathrm{l}$ in programmable temperature vaporization (PTV) inlet, Solvent Split mode. Starting (base) temperature: $65^{\circ} \mathrm{C}$; solvent valve temperature: $100^{\circ} \mathrm{C}$; evaporation rate $1{ }^{\circ} \mathrm{C} / \mathrm{sec}$; evaporation temperature $70^{\circ} \mathrm{C}$; transfer rate $14.5^{\circ} \mathrm{C} / \mathrm{s}$; temperature was held for $1 \mathrm{~min}$ at $290^{\circ} \mathrm{C}$ during transfer; carrier gas: helium $(1.0 \mathrm{ml} / \mathrm{min})$; oven program: $40^{\circ} \mathrm{C}$ (1min), $40^{\circ} \mathrm{C} / \mathrm{min}$ to $80^{\circ} \mathrm{C}, 15^{\circ} \mathrm{C} / \mathrm{min}$ to $160^{\circ} \mathrm{C}, 5^{\circ} \mathrm{C} / \mathrm{min}$ to $220^{\circ} \mathrm{C}, 15^{\circ} \mathrm{C} / \mathrm{min}$ to $315^{\circ} \mathrm{C}(10 \mathrm{~min})$. Data acquisition time 4.3 scans/s. Mass spectrometric conditions: transfer liner and ion source temperature: $300^{\circ} \mathrm{C}$ and $250^{\circ} \mathrm{C}$, respectively. Eight mass fragments were analyzed in 2 groups of 4 ions using SIM. The commercial GC-MS software Xcalibur 1.3 was used for data processing.

\subsection{Statistical analysis}

Correlation analysis was performed using Spearman's Rank-order test.

\section{Results and Discussion}

\subsection{Synchronous fluorescence spectrometry}

Synchronous fluorescence spectrometry (SFS) analysis of the tissue extracts of the worms exposed to pyrene revealed peaks representing 1-hydroxypyrene and conjugated pyrene metabolites (Fig. 1). The peak representing conjugates is blue shifted in relation to the 1hydroxypyrene peak and has a maximum intensity at an excitation wavelength of $346 \mathrm{~nm}$ (Fig. 1 A v). The blue shift of conjugated 1-hydroxypyrene is in accordance with previous studies (Ariese et al., 1993; Giessing et al., 2003b). Although Ariese et al. (1993) reported increase in fluorescence intensity of glucuronide conjugated 1-hydroxypyrene 2-fold, and Strickland et al. (1994) observed 5-fold higher intensity in 1-hydroxypyrene glucuronide than in free 1hydroxypyrene, there was only a minor intensity increase in glucuronide conjugate of 1hydroxypyrene, in our study (Fig.1). As expected, conjugated metabolites were not detectable in the tissue sample after glucuronidase treatment except for pyrene-1-sulfate that remained in the sample in minor quantities. 1-hydroxypyrene was the only peak present in the spectrum after enzymatic hydrolysis and had its maximum fluorescence in the SFS spectrum at $351 \mathrm{~nm}$ excitation wavelength (Fig. $1 \mathrm{~A}$ iv). The wavelength of maximum fluorescence for 1-hydroxypyrene is in accordance with previous studies, where the distinctive excitation maxima of 1-hydroxypyrene were at $352 \mathrm{~nm}$ (Strickland et al., 1994).

Fig. 1.

The maximum fluorescence intensity for the pyrene peak in the reference standard sample was at $336 \mathrm{~nm}$ (Fig. $1 \mathrm{~A}$ ii). However, pyrene was never detected in the tissue samples using SFS or HPLC/F, after enzymatic treatment of the sample. Pyrene was below the detection level in these samples, probably due to precipitation with the enzyme and other organic matter during the enzymatic hydrolysis procedure.

An overlay of spectra of the tissue samples from the worms exposed to five different PAHs, before and after enzymatic treatment is shown in Fig. $1 \mathrm{~B}$, together with the spectra of unexposed worms from the same experiment and 1-hydroxypyrene reference standard solution (same as in Fig. 1 A). The conjugated metabolite peak is, as well as in the pyrene exposure experiment, blue shifted in relation to 1-hydroxypyrene, having its maximum fluorescence at 346.9 nm (Fig. 1 B iv).

The first broad band at around $280 \mathrm{~nm}$ present in all samples (Fig. 1 A, Fig. 1 B) represents traces of protein-lipid matrix, which cannot be completely removed after precipitation 
by ice-cold ethanol and centrifugation. Spectra from unexposed worms (Fig. 1 A i, Fig. 1 B i) showed no peaks other than this broad protein band with varying intensity, in agreement with a previous study (Giessing et al., 2003b).

The main feature of both figures (Fig. 1 A and Fig. 1 B) is spectral similarity. After preparative treatment, tissue extracts from organisms exposed to several different PAHs reveal similar characteristics as samples from animals exposed only to pyrene. Evidently from the Fig. 1 $\mathrm{B}$, no other fluorescence is interfering with the 1-hydroxypyrene peak in the spectra. This fact clearly demonstrates the possibility of measuring a proposed biomarker compound - 1hydroxypyrene, in tissue samples from organisms exposed to complex mixtures of multiple PAHs.

\subsection{High performance liquid chromatography}

To validate fluorometric measurements in relation to possible interferences of different non target compounds the SFS method for screening for PAH contamination was verified using HPLC, and the samples were enzymatically hydrolyzed prior to quantification (Giessing et al., 2003b). The conjugated metabolites, 1-hydroxypyrene and unchanged pyrene in the tissues were identified using HPLC/F. The conjugated metabolites were identified according to the order of elution as established in the method developed in our laboratory by Jørgensen et al. (2005). A typical HPLC/F chromatogram of the tissue extract shows five peaks representing: 1hydroxypyrene glucuronide (retention time $=16.2 \mathrm{~min}$ ), 1-hydroxypyrene sulfate (retention time $=$ $18.86 \mathrm{~min}$ ) and 1-hydroxypyrene glucoside (retention time $=22.46 \mathrm{~min}$ ). The 1-hydroxypyrene peak elutes later than the conjugated metabolites and the unmetabolized pyrene peak is the last one in the chromatogram (retention time $=37.3 \mathrm{~min}$ ) (Fig. 2). Pretreatment of the tissue extracts with $\beta$-glucuronidase-arylsulfatase reduced or eliminated the conjugated metabolite peaks with a concomitant increase in the 1-hydroxypyrene peak (retention time $=31.62 \mathrm{~min}$ ). It was possible to eliminate 1-hydroxypyrene glucuronide and 1-hydroxypyrene glucoside metabolites but the sulfate conjugate peak could not be sufficiently hydrolysed, thus the peak was only reduced in size.

Fig. 2.

As fluorescence efficiencies are higher for the conjugates than for 1-hydroxypyrene, the amount of pyrene conjugates can be expressed in 1-hydroxypyrene equivalents, by adjusting the pyrene conjugate area with conversion factors (Stroomberg et al., 2003). In this study the peak areas of pyrene-1-glucuronide, pyrene-1-glucoside and pyrene-1-sulfate were divided by factors $1.8,1.8$ and 1.7 respectively (Jørgensen, personal communication).

The amount of remaining conjugates in the tissues of animals exposed to the five PAHs is higher than in animals exposed to pyrene only. Animals exposed to five different PAHs produce many other conjugated metabolites than those of pyrene, hence, competition of substrates for the enzyme is possible, and increased amounts of enzyme should be added.

Complete hydrolysis of the conjugated 1-hydroxypyrene was not an obligatory condition for this study, as there were no noticeable spectral interferences for the SFS analysis that could be caused by conjugated metabolites after deconjugation with enzymatic hydrolysis. The amount of remaining conjugates was insignificant for the reproducibility of the measurement, thus the method was not affected by incomplete hydrolysis.

SFS analysis of 1-hydroxypyrene and its conjugates was carried out using $\boldsymbol{\Delta} \boldsymbol{\lambda}$ of 34 (Giessing et al., 2003b; Lin et al., 1994) and $37 \mathrm{~nm}$ (Ariese et al., 1993) in different studies. Here, the SFS spectra were recorded with a wavelength interval $\Delta \lambda$ of $34 \mathrm{~nm}$.

A HPLC/F procedure for detection of PAH metabolites in fish bile was developed by Krahn et al. (1984) as a relatively inexpensive and rapid screening method, which does not require complete separation or identification of individual metabolites, as it was a rapid separation of non- 
hydrolyzed bile sample by reverse-phase HPLC, and the overall fluorescence over a specific elution interval was integrated to give a sum parameter that is expressed as the amount of "equivalent" to the chosen standard compound (Ariese et al., 2005). Furthermore, HPLC/F showed to be useful for accurate measure of individual deconjugated PAH metabolites in enzymatically hydrolyzed bile samples (Ariese et al., 2005). Thus, the HPLC/F method has been shown to be sensitive and reliable for analysis of PAH metabolites in different matrices, such as fish bile (Ariese et al., 1993; Lin et al., 1994; Krahn et al., 1984; Krahn et al., 1986) and marine and terrestrial invertebrates tissues (Stroomberg et al., 1999; Giessing et al., 2003b; Stroomberg et al., 2003). However, the SFS method has its advantages such as simplicity and speed, and it also requires less instrumentation and maintenance than HPLC/F. Results represented in figures 1 and 2 clearly demonstrate, that SFS could be a possible substitution method instead of HPLC/F for analysis of 1-hydroxypyrene, since it has sufficiently high sensitivity for this compound, and separation of 1-hydryxypyrene from other PAH compounds and metabolites is not necessary.

\subsection{Using 1-hydroxypyrene concentrations to characterize PAH exposure}

In the concentration-response relationship experiment, worms exposed to pyrene showed increasing accumulation of pyrene and production of 1-hydroxypyrene with increasing exposure concentration (Fig. 3). The exposure period was 5 days, because a pyrene accumulation study by Christensen et al. (2002) showed that pyrene accumulation reached a steady-state in the tissues of N. diversicolor within 4-5 days (Christensen et al., 2002).

These results, increasing tissue accumulation of pyrene and production of 1hydroxypyrene with increasing exposure concentration, agree with those of a previous study of Giessing et al. (2003b). This observation indicates usefulness of this metabolite as a biomarker of pyrene exposure. The concentrations of both 1-hydroxypyrene and pyrene were below the detection limit in samples of unexposed worms. Pyrene was not detectable by HPLC/F in tissue samples after enzymatic hydrolysis, probably due to precipitation with organic matter during the enzymatic hydrolysis procedure, as is the case of SFS measurements. This is in agreement with the study of Giessing and Mayer (2004) who observed coprecipitation of pyrene with the matrix components after the centrifugation.

Fig. 3.

Tissue concentrations of 1-hydroxypyrene from the pyrene only exposure experiment were quantified using SFS and HPLC/F. In samples from the lowest exposure concentration: $1 \mathrm{mg}$ pyrene $\mathrm{kg}^{-1}$ sediment $(\mathrm{dw})$, 1-hydroxypyrene was below the detection limit when using SFS, however, it was possible to measure 1-hydroxypyrene at the higher exposure concentrations: 10 and $30 \mathrm{mg}$ pyrene $\mathrm{kg}^{-1}$ sediment $(\mathrm{dw})$. A positive and highly significant correlation was observed (Spearmans rank-order correlation, $\mathrm{r}_{\mathrm{s}}=0.903 ; P<0.01$ ) between 1-hydroxypyrene concentrations measured by the two methods (Fig.4). These results are a fine confirmation of the previous results in similar experiment in the study of Giessing et al. (2003b).

Fig. 4.

The 1-hydroxypyrene concentrations measured by SFS are on average 1.4 times higher than those measured by HPLC/F with all but two of the data points above the 1:1 line on Fig.4. Conjugated 1-hydroxypyrene has higher fluorescence intensity than the free metabolite (Ariese et al., 1993; Strickland et al., 1994). As mentioned earlier, in the absence of enzymatic hydrolysis, the SFS signal measured is the combined signal of all compounds containing the 1-hydroxypyrene fluorophore. Thus, 1-hydroxypyrene concentrations determined by SFS would be expected to be higher than those determined by HPLC/F (Giessing et al., 2003b). Although we have employed enzymatic hydrolysis in our study, it was not possible to achieve $100 \%$ complete hydrolysis of 
conjugates. Consequently, a fraction of conjugates still remained in the samples, adding to the fluorescence signal of the 1-hydroxypyrene containing fluorophore. Thus, 1-hydroxypyrene concentrations determined by SFS, being sum of all 1-hydroxypyrene containing species, would be expected to be higher than concentrations determined by HPLC also in our study. Another explanation for the difference may be the way the calibration solutions were prepared. As described in the Materials and Methods, the standard dilutions for SFS analysis contained proteinlipid matrix in amounts equal to those in the samples. If standard dilutions were prepared separately from samples, differences in preparation conditions may develop, that could results in varying degree of precipitation of the protein-lipid matrix. Consequently, an elevated baseline in SFS spectra of the standard dilutions could lead to a slight increase in the 1-hydroxypyrene concentrations measured. Thus, for our further investigations, we prepared the matrix solutions for SFS calibration curves at the same time as the tissue samples of exposed worms and in precisely the same manner.

Giessing et al. (2003b) first reported the use of SFS analysis for measuring pyrene metabolites in $N$. diversicolor exposed to pyrene, as a substitute to HPLC/F analysis, and studied the correlation of results derived by these two methods. When comparing our correlation results to those of Giessing et al. (2003b), some differences in correlation strength, as well as values achieved by SFS measurement in contrast to values derived by HPLC/F are noticeable. In the present study the SFS values differ less from the HPLC/F values, because the enzymatic hydrolysis was applied to the samples. The correlation is also stronger in our study with $P<0.01$ compared to $P=0.081$ of Giessing et al. (2003b).

In light of the complex composition of environmental PAH mixtures, it is necessary to examine the following before the 1-hydoxypyrene accumulated in the tissues of exposed worms can be regarded as a suitable indicator for assessing polychaete total PAH exposure: (i) the relationship between 1-hydroxypyrene and several parent PAHs accumulated in animal tissues, together with the corresponding total PAH sediment exposure levels and (ii) the relationship between 1-hydroxypyrene levels and total PAH levels in the tissues of animals exposed to different PAHs.

Accumulation of total PAH (TPAH) in relation to the sediment exposure concentration is illustrated in Fig. 5. The TPAH tissue content was analyzed by both HPLC/F and GC/MS. There is a strong positive concentration - response relationship in this experiment. Animals exposed to five PAHs showed increasing accumulation of all five compounds with increasing exposure concentration (Fig. 5). Each of the PAH compounds showed different rates of accumulation in animal tissues, however, the total concentration of all 5 PAHs followed the increasing exposure concentration.

Fig. 5.

As mentioned in the Materials and Methods section, worm tissues were extracted in two steps: first in methanol, in order to extract soluble metabolites and, secondly, in dichloromethane (DCM) in order to collect the remaining parent PAHs left in the tissues after the first extraction step. It was not possible to analyze samples diluted in DCM using HPLC/F running methanol/water gradient. Therefore, samples from the second extraction, diluted in DCM were directly analyzed using GC/MS without further treatment, in order to keep most of the extracted PAHs, as the amounts were predicted to be very low. There was a strong positive and significant correlation between TPAH measured by GC/MS and HPLC/F (Spearman's Rank order correlation $\mathrm{r}_{\mathrm{s}}=1, \mathrm{P}<0.01$ ), indicating validity of both methods for this analysis (Fig. 6).

Fig. 6. 
The sediment total PAH content after the experiment was analyzed using GC/MS, recovery of the method ranged between $60-77 \%$ showing good recovery of the extraction method for the sediment GC/MS analysis. The total PAH content of the sediment after the experiment was lower than the nominal concentrations (Fig. 5), due to PAH loss during the experiment, such as accumulation by animals and overlying water removal, and due to the spiking procedure.

A strong positive and significant correlation was observed between the sum concentration of the five PAHs (TPAH) and 1-hydroxypyrene concentrations measured using HPLC/F and GC/MS (for both methods: Spearman's rank-order correlation $\mathrm{r}_{\mathrm{s}}=0.950 ; P<0.01$.) (Fig. 7).

Fig. 7.

Note, that 1-hydroxypyrene is produced only from pyrene and that TPAH is the sum of equal amounts of phenanthrene, anthracene, pyrene, $\mathrm{B}[\mathrm{a}] \mathrm{p}$ and $\mathrm{B}[\mathrm{k}] \mathrm{f}$. In figure 7 , numbers for 1hydroxypyrene concentration are 3-4 times lower than those for TPAH, since 1-hydroxypyrene is produced only from pyrene. A strong positive correlation between concentrations of produced 1hydroxypyrene and accumulated TPAH was observed. The increase in the concentration of 1hydroxypyrene according to increase in the accumulated amount of TPAH, indicates that 1hydroxypyrene has potential as a useful biomarker for assessment of exposure to several different PAHs (Fig. 7). It is evident from these results that the presence of other PAHs than pyrene in sediment does not restrain the possibility of using 1-hydroxypyrene as a biomarker of total PAH exposure. The animal organism is likely to be more stressed being exposed to different xenobiotics than to pyrene only. Nevertheless, as long as there is pyrene in the PAH mixture, and pyrene biotransformation is activated in the organism, 1-hydroxypyrene can indicate the accumulation of PAHs into the organism over all uptake routes. The result above is not surprising, since all worms under study were exposed to the same mixture of PAHs, with the same proportions of each PAH. In environmental mixtures, on the other hand, the proportion of pyrene to other PAHs varies between different samples. Therefore, the source of PAH contamination, with its particular proportions of pyrene compound, should be taken into consideration, when applying this method to field samples. Nevertheless, since pyrene is a constituent of all environmental PAH mixtures, present in relatively high amounts (Levin, 1995; Jongeneelen et al., 1985), the analysis of its metabolites could provide a useful screening tool for PAH exposure. Note that the outcome provided by the measurements of 1-hydroxypyrene supposedly is used only for screening of PAH exposure, meaning, that it can characterize the approximate level of PAHs in the sediment. For the 1-hydroxypyrene value to represent a more quantitative index of exposure to PAHs in an environmental mixture, many more studies should be conducted and especially the proportions of single PAHs in the mixture should be taken into account.

Previous studies have shown that 1-hydroxypyrene can be used as a relative measure for the total uptake of PAHs in humans (Levin, 1995; Jongeneelen, 2001) and fish (Ariese et al., 1993). In human research, correlation studies have been made in order to establish the relationship between pyrene and 1-hydroxypyrene and total PAH levels. For example, Tsai et al. (2004) performed a correlation analysis to examine the relationship between total PAH exposure levels and pyrene exposure levels in occupationally exposed workers, and the good correlation established suggested, that the individual compound pyrene could be regarded as a suitable indicator for total PAH exposure (Tsai et al., 2004). Another correlation analysis conducted by Tsai et al. (2004) in order to examine the relationship between workers' urinary 1-hydroxypyrene concentration and their corresponding total PAH exposure levels, indicated that the increase in urinary 1-hydroxypyrene concentrations during the workweek could be fairly well explained by PAH exposures arising from vehicle exhaust. Results presented in our study indicate that relationships between 1-hydroxypyrene and total PAH exposure levels similar to those achieved in human epidemiology can be established in benthic marine invertebrates. Thus, 1-hydroxypyrene can be used as a relative measure of the total uptake of PAHs using exposed marine polychaetes 
as well as fish bile from exposed fish. The value of the proposed simple method is, that it integrates the bioavailability of sediment associated PAHs into the biomarker of PAH exposure. It is well known, that similar sediment concentrations of PAHs can lead to very different internal dose depending on the composition of the sediment, especially organic content and soot. To estimate internal dose from total sediment concentrations without having a biological indicator requires very extensive physicochemical measurements and calculations. The method proposed in this study is not to be considered as a contribution to understanding of the exact fate of individual compounds in a mixture of PAHs, but as method that takes advantage of the simple metabolic pattern of pyrene, in order to crudely estimate general PAH exposure in the marine sediments.

To test the feasibility of quantifying 1-hydroxypyrene from worms exposed to different PAHs, tissue concentrations of 1-hydroxypyrene from the five PAHs exposure experiment were also quantified using HPLC/F and SFS. There was a strong positive and significant correlation (Spearman's rank-order correlation, $\mathrm{r}_{\mathrm{s}}=0.917 ; P<0.01$ ) between 1 -hydroxypyrene concentrations measured by the two methods (Fig. 8).

Fig. 8.

There could be several explanations why data points representing data derived from worms exposed to the highest PAH concentration $\left(50 \mathrm{mg} \mathrm{kg}^{-1}\right)$ deviate more from the $1: 1$ ratio line than data points from lower exposure concentrations. For instance, at the higher concentrations the competition of different substrates for an enzyme may occur, causing higher variability of the pyrene metabolites in the animal tissue. Hence, the interferences from those metabolites could contribute to the SFS measurements, while the same metabolites would not interfere with 1hydroxypyrene during chromatographic separation on HPLC/F.

Nevertheless, the most important result achieved by these correlations is that the common tendency is validated statistically. There is always a strong and significant positive correlation between 1-hydroxypyrene and TPAH in the tissues and between 1-hydroxypyrene concentrations measured by SFS and HPLC/F (Table 1).

Table 1.

Synchronous fluorescence spectroscopy of whole worm homogenate is a straightforward method for detection of pyrene metabolites in marine deposit-feeding polychaetes, and the complete analysis of one sample takes only few minutes, and requires much less instrumentation than HPLC/F analysis. Giessing et al. (2003b) concluded that HPLC UV/F surpasses SFS as a quantitative analytical technique. Nevertheless, when samples are treated with de-conjugating enzymes, and large part of the protein-lipid matrix is precipitated, SFS can be applied for reliable quantitative analysis of 1-hydroxypyrene, as it has been shown in the present study. During SFS analysis conjugates that were not affected by enzyme treatment can contribute to fluorescence of 1-hydroxypyrene, therefore this technique might not offer a precise quantification of this metabolite. HPLC/F analysis offer more precise measures of the 1-hydroxypyrene amounts in the worm tissues than does SFS, since it separates conjugated metabolites from 1-hydroxypyrene. However, SFS can indeed provide a useful and rapid screening tool for assessment of PAH exposure in marine invertebrates.

Contrary to fish bile samples, the SFS method for polychaetes requires homogenization of the tissue and enzymatic hydrolysis, making this method more labor intensive and expensive. However, Nereis diversicolor is sessile and therefore a good indicator organism for local pollution. In moderately polluted sediments, despite the fact that the fluorescence signal was already below the detection limit at the spiking level of $1 \mathrm{mg}$ pyrene $\mathrm{kg}^{-1}$ sediment (dw) as illustrated in Fig. 4, the SFS method may still be applied by pooling several individual worms sampled at the same place in order to increase the total metabolite concentration. 
Several studies have indicated that the sensitivity of the SFS method is sufficient for field monitoring of PAH exposure using fish bile metabolites (Ariese et al., 1993; Lin et al., 1994). The present study has shown that SFS analysis of only one metabolite - 1-hydroxypyrene - in polychaete worm homogenate is sufficiently sensitive for assessment of total PAH exposure. Presence of other PAHs in the contaminated sediment did not compromise the sensitivity of the method, and the results achieved by SFS even at the highest exposure concentration correlated well with the more precise HPLC/F method. Future experiments will reveal if similar correlations between total PAH and 1-hydroxypyrene can be observed in benthic polychaetes from field sites. However, the feasibility of such method, as measuring 1-hydroxypyrene by SFS in order to screen total PAH exposure, will allow allocation of resources to other areas of risk assessment of sediment, than costly preliminary chemical analysis of the environmental media and animal tissues.

Taking into account the ongoing debate on the usefulness of biomarkers in environmental risk assessment (ERA), where some authors emphasize advantages of biomarker application in ERA (Martin-Diaz et al., 2004), others are criticizing the biomarker approach, suggesting to focus our efforts on other methods (Forbes et al., 2006), and others while accepting criticism, suggest further development of biomarkers applications in ERA (Van Gestel and Van Brummelen, 1996), our study exhibits usefulness and applicability of the simple exposure biomarker 1hydroxypyrene. Biomarkers are often criticized for not being useful predictors of ecological effect and for difficulties in linking responses from the individual to population levels (Forbes et al., 2006). It is important to note that the present study proposes 1-hydroxypyrene as biomarker of exposure and not effect. Therefore, it is not claimed that using 1-hydroxypyrene as a biomarker compound would allow prediction of any adverse effect, and also especially on the higher level of biological organization (e.g. population, ecosystem). Future experiments will show whether or not different proportions of the compound pyrene in different environmental mixtures of PAHs influence the usefulness of using 1-hydroxypyrene as surrogate for assessment of total PAH levels. However, the method presented here, if applicable to field samples, could serve as an effective, non-laborious and relatively low-cost screening tool for preliminary stages of sediment ERA.

Acknowledgment - Supported by the Danish Research Council for Nature and Universe to Ole Andersen.

\section{References}

Aas, E., Beyer, J., Goksoyr, A., 1998. PAH in fish bile detected by fixed wavelength fluorescence. Marine Environmental Research, 46, 225-228.

Ariese, F., Kok, S., Verkaik, M., Gooijer, C., Velthorst, N., Hofstraat, J., 1993. Synchronous Fluorescence Spectrometry of Fish Bile: a Rapid Screening Method for the Biomonitoring of PAH Exposure. Aquatic Toxicology, 26, 273-286.

Ariese, F., Beyer, J., Jonsson, G., Porte Visa, C., Krahn, M., 2005. Review of analytical methods for determining metabolites of polycyclic aromatic compounds (PACs) in fish bile. ICES Techniques in Marine Environmental Sciences, Nr.39.

Boogaard, P.J., Vansittert, N.J., 1995. Urinary 1-Hydroxypyrene as Biomarker of Exposure to Polycyclic Aromatic-Hydrocarbons in Workers in Petrochemical Industries - Base-Line Values and Dermal Uptake. Science of the Total Environment, 163, 203-209. 
Christensen, M., Andersen, O., Banta, G.T., 2002. Metabolism of pyrene by the polychaetes Nereis diversicolor and Arenicola marina. Aquatic Toxicology, 58, 15-25.

Eickhoff, C.V., Gobas, F.A.P.C., Law, F.C.P., 2003. Screening pyrene metabolites in the hemolymph of dungeness crabs (Cancer magister) with synchronous fluorescence spectrometry: Method development and application. Environmental Toxicology and Chemistry, 22, 59-66.

Giessing, A.M.B., Mayer, L.M., 2004. Oxidative coupling during gut passage in marine depositfeeding invertebrates. Limnology and Oceanography, 49, 716-726.

Giessing, A.M.B., Mayer, L.M., Forbes, T.L., 2003a. 1-Hydroxypyrene glucuronide as the major aqueous pyrene metabolite in tissue and gut fluid from the marine deposit-feeding polychaete Nereis diversicolor. Environmental Toxicology and Chemistry, 22,1107-1114.

Giessing, A.M.B., Mayer, L.M., Forbes, T.L., 2003b. Synchronous fluorescence spectrometry of 1-hydroxypyrene: a rapid screening method for identification of $\mathrm{PAH}$ exposure in tissue from marine polychaetes. Marine Environmental Research, 56, 599-615.

Goen, T., Gundel, J., Schaller, K. H., Angerer, J., 1995. The Elimination of 1-Hydroxypyrene in the Urine of the General-Population and Workers with Different Occupational Exposures to PAH. Science of the Total Environment, 163, 195-201

Fillmann, G., Watson, G. M., Howsam, M., Francioni, E., Depledge, M. H., Readman, J. W., 2004. Urinary PAH metabolites as biomarkers of exposure in aquatic environments.

Environmental Science \& Technology, 38, 2649-2656.

Forbes, V.E., Palmqvist, A., Bach, L., 2006. The use and misuse of biomarkers in ecotoxicology. Environmental toxicology and Chemistry, 25, 272-280.

Jongeneelen, F. J., Anzion, R. B. M., Leijdekkers, C. M., Bos, R. P., Henderson, P. T., 1985. 1Hydroxypyrene in Human-Urine after Exposure to Coal-Tar and a Coal-Tar Derived Product. International Archives of Occupational and Environmental Health, 57, 47-55.

Jongeneelen, F.J., Anzion, R.B.M., Henderson, P.T., 1987. Determination of Hydroxylated Metabolites of Polycyclic Aromatic-Hydrocarbons in Urine. Journal of ChromatographyBiomedical Applications, 413, 227-232.

Jongeneelen, F.J., Bos, R.P., Henderson, P.T., 1988. Metabolites of Polycyclic AromaticHydrocarbons in Urine of Exposed Workers. Toxicological and Environmental Chemistry, 16, 295-307.

Jongeneelen, F.J., 2001. Benchmark guideline for urinary 1-hydroxypyrene as biomarker of occupational exposure to polycyclic aromatic hydrocarbons. Annals of Occupational Hygiene, 45, $3-13$.

Jørgensen, A., Giessing, A.M.B., Rasmussen, L.J., Andersen, O., 2005. Biotransformation of the polycyclic aromatic hydrocarbon pyrene in the marine polychaete Nereis virens. Environmental Toxicology and Chemistry, 24, 2796-2805.

Krahn, M. M., Myers, M. S., Burrows, D. G., Malins, D. C., 1984. Determination of 
Metabolites of Xenobiotics in the Bile of Fish from Polluted Waterways. Xenobiotica, 14, 633646.

Krahn, M.M., Kittle, L.J., Macleod, W.D., 1986. Evidence for Exposure of Fish to Oil Spilled into the Columbia River. Marine Environmental Research, 20, 291-298.

Levin, J.O., 1995. First International Workshop on Hydroxypyrene as a Biomarker for PAH Exposure in Man - Summary and Conclusions. Science of the Total Environment, 163, 165-168.

Levin, J.O., Rhen, M., Sikstrom, E., 1995. Occupational PAH Exposure - Urinary 1-

Hydroxypyrene Levels of Coke-Oven Workers, Aluminum Smelter Pot-Room Workers, Road Pavers, and Occupationally Non-Exposed Persons in Sweden. Science of the Total Environment, $163,169-177$.

Lin, E.L.C., Cormier, S.M., Racine, R.N., 1994. Synchronous Fluorometric Measurement of Metabolites of Polycyclic Aromatic-Hydrocarbons in the Bile of Brown Bullhead. Environmental Toxicology and Chemistry, 13, 707-715.

M. L. Martín-Díaz, Blasco, J., Sales, D., DelValls, T. A., 2004. Biomarkers as tools to assess sediment quality. Laboratory and field surveys. Trends in Analytical Chemistry, 23, 807-818.

Neff, J.M., 1985. Polycyclic Aromatic Hydrocarbons. In: Rand, G.M., Petrocelli, S.R. (Eds.), Fundamentals of aquatic toxicology: methods and applications. Taylor and Francis Ltd., pp. 416454.

Rodriguez, J.J.S., Sanz, C.P., 2000. Fluorescence techniques for the determination of polycyclic aromatic hydrocarbons in marine environment: an overview. Analusis, 28, 710-717.

Strickland, P. T., Kang, D., Bowman, E. D., Fitzwilliam, A., Downing, T. E., Rothman, N., Groopman, J. D., Weston, A., 1994. Identification of 1-Hydroxypyrene Glucuronide as a Major Pyrene Metabolite in Human Urine by Synchronous Fluorescence Spectroscopy and Gas-Chromatography Mass-Spectrometry. Carcinogenesis, 15, 483-487.

Strickland, P., Kang, D.H., 1999. Urinary 1-hydroxypyrene and other PAH metabolites as biomarkers of exposure to environmental PAH in air particulate matter. Toxicology Letters, 108, 191-199.

Stroomberg, G. J., Ariese, F., Van Gestel, C. A. M., Van Hattum, B., Velthorst, N. H., Van Straalen, N. M., 2003. Pyrene biotransformation products as biomarkers of polycyclic aromatic hydrocarbon exposure in terrestrial Isopoda: Concentration-response relationship, and field study in a contaminated forest. Environmental Toxicology and Chemistry, 22, 224-231.

Stroomberg, G. J., de Knecht, J. A., Ariese, F., Van Gestel, C. A. M., Velthorst, N. H., 1999. Pyrene metabolites in the hepatopancreas and gut of the isopod Porcellio scaber, a new biomarker for polycyclic aromatic hydrocarbon exposure in terrestrial ecosystems.

Environmental Toxicology and Chemistry, 18, 2217-2224.

Tsai, P. J., Shieh, H. Y., Lee, W. J., Chen, H. L., Shih, T. S., 2002. Urinary 1-hydroxypyrene as a biomarker of internal dose of polycyclic aromatic hydrocarbons in carbon black workers. Annals of Occupational Hygiene, 46, 229-235. 
Tsai, P. J., Shih, T. S., Chen, H. L., Lee, W. J., Lai, C. H., Liou, S. H., 2004. Urinary 1hydroxypyrene as an indicator for assessing the exposures of booth attendants of a highway toll station to polycyclic aromatic hydrocarbons. Environmental Science \& Technology $38,56-61$.

Van Gestel, C.A.M., Van Brummelen, T.C., 1996. Incorporation of the biomarker concept in ecotoxicology calls for a redefinition of terms. Ecotoxicology, 5, 217-225.

Viau, C., Vyskocil, A., 1995. Patterns of 1-Hydroxypyrene Excretion in Volunteers Exposed to Pyrene by the Dermal Route. Science of the Total Environment, 163, 187-190.

Viau, C., Vyskocil, A., Martel, L., 1995. Background Urinary 1-Hydroxypyrene Levels in NonOccupationally Exposed Individuals in the Province of Quebec, Canada, and Comparison with Its Excretion in Workers Exposed to PAH Mixtures. Science of the Total Environment, 163, 191194.

Walker, C. H., Hopkin, S. P., Sibly, R. M., Peakall, D. B., 2001. Principles of Ecotoxicology. Second Edition. London, Taylor and Francis.

Watson, G. M., Andersen, O. K., Galloway, T. S., Depledge, M. H., 2004. Rapid assessment of polycyclic aromatic hydrocarbon $(\mathrm{PAH})$ exposure in decapod crustaceans by fluorimetric analysis of urine and haemolymph. Aquatic Toxicology, 67, 127-142. 

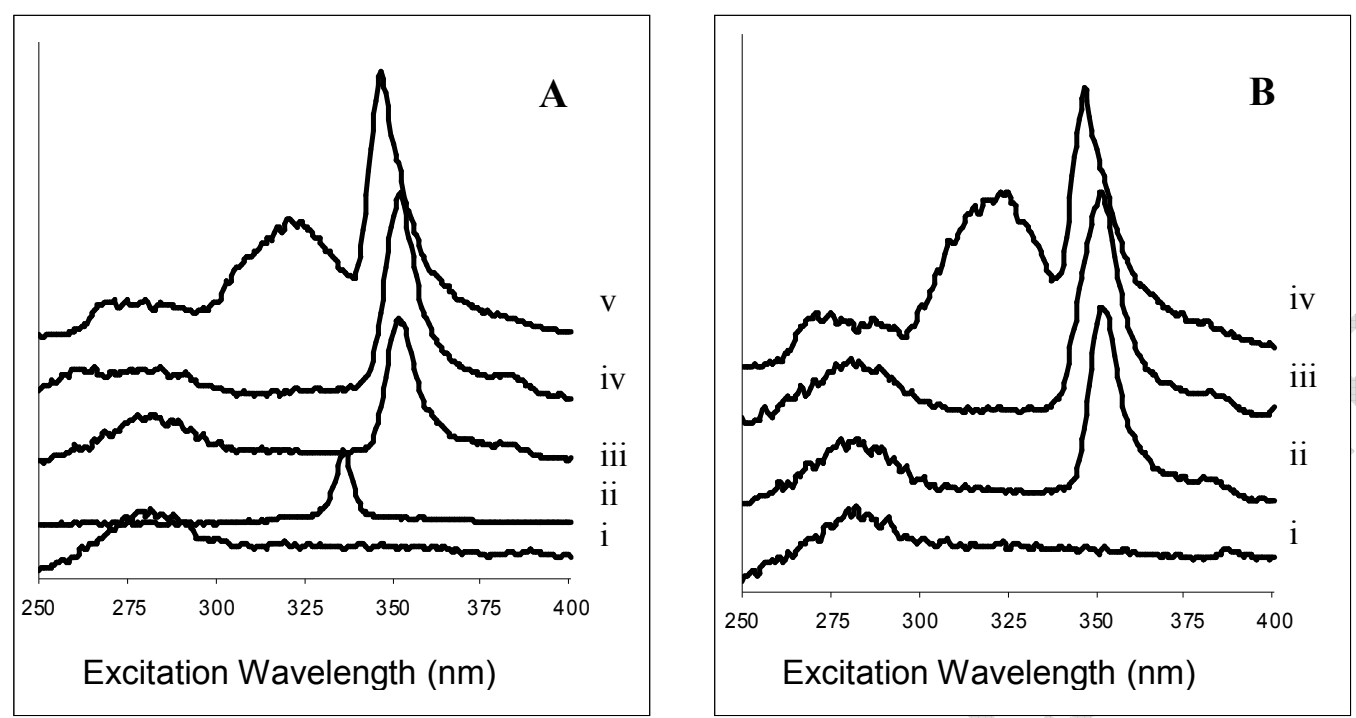

Fig.1.

Synchronous fluorescence spectra of: A) tissue extracts of pyrene exposed worms. Unexposed worm (i); pyrene reference standard $1.4 \mu \mathrm{g} \mathrm{ml}^{-1}$ (ii); 1-hydroxypyrene reference standard, $60 \mathrm{ng} \mathrm{ml}^{-1}$ (iii), and tissue extracts, after (iv) and before (v) enzymatic treatment, spiking level of the sediment - $30 \mathrm{mg} \mathrm{kg}^{-1}$; B) extracts from worms exposed to five PAHs - before (iv) and after (iii) enzymatic treatment, spiking level of the sediment - $50 \mathrm{mg} \mathrm{kg}^{-1}$, showing conjugated metabolites and the 1-hydroxypyrene peak, respectively; unexposed worm tissue sample (i) and 1-hydroxypyrene reference standard $60 \mathrm{ng} \mathrm{ml}^{-1}$ (ii). 


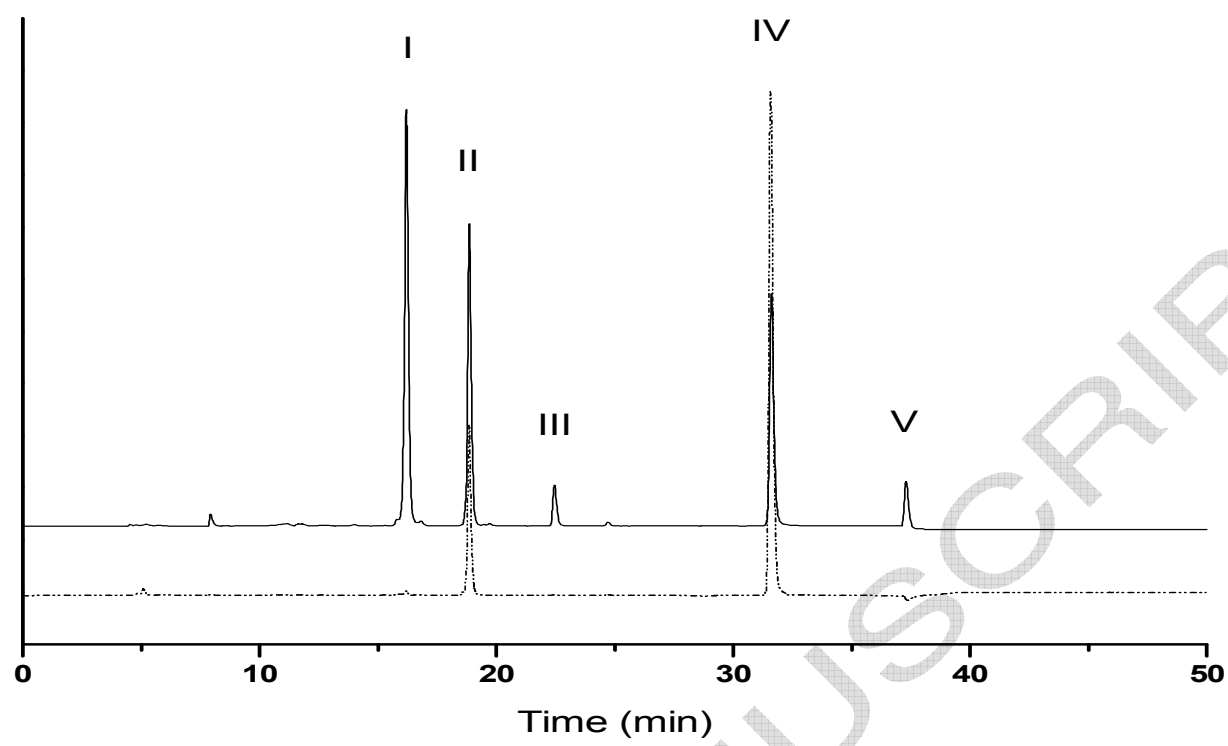

Fig.2.

Fluorescence chromatograms of tissue samples of worms exposed to pyrene, spiking level of the sediment $10 \mathrm{mg} \mathrm{kg}^{-1}(\mathrm{dw})$.

Tissue sample prior treatment with $\beta$-glucuronidase-arylsulfatase (full line) revealing pyrene-1-glucuronide (I), pyrene-1-sulfate (II), pyrene-1-glucoside (III), 1-hydroxypyrene (IV) and pyrene (V). Tissue sample treated with enzyme (dashed line) revealing only two peaks - decreased peak of pyrene-1-sulfate and increased 1-hydroxypyrene. 


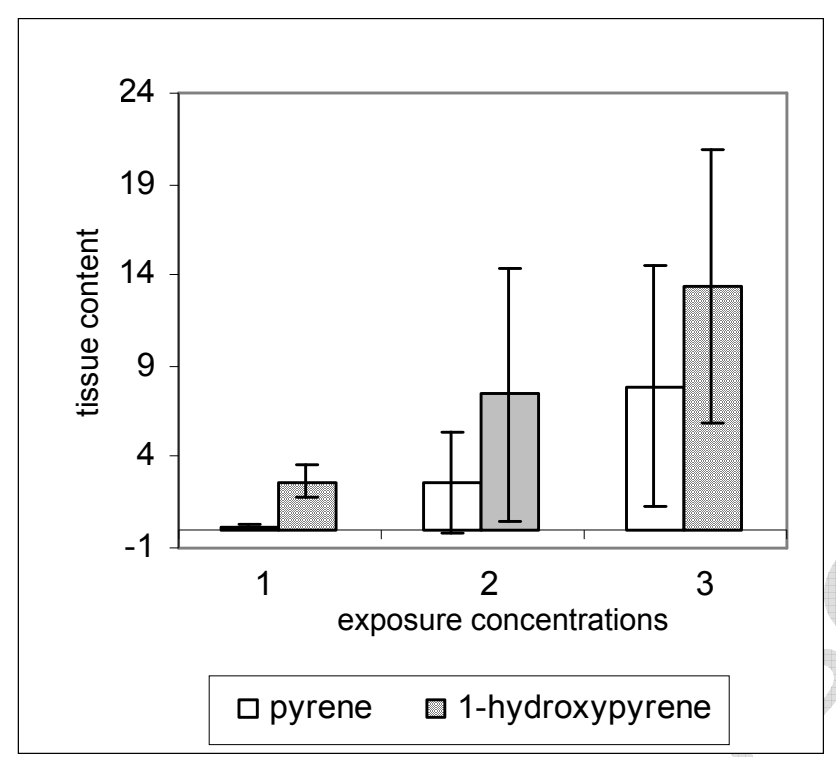

Fig.3.

Exposure to pyrene alone. Concentration - response relationship. Tissue extracts used had not been enzymatically hydrolysed. Accumulation of pyrene and production of 1-hydroxypyrene in animal tissues (ug $\mathrm{g}^{-1} \mathrm{Ww}$ ), measured by HPLC/F, follow the sediment exposure concentrations $\left(\mathrm{mg} \mathrm{kg}^{-1} \mathrm{dw}\right.$ ). 


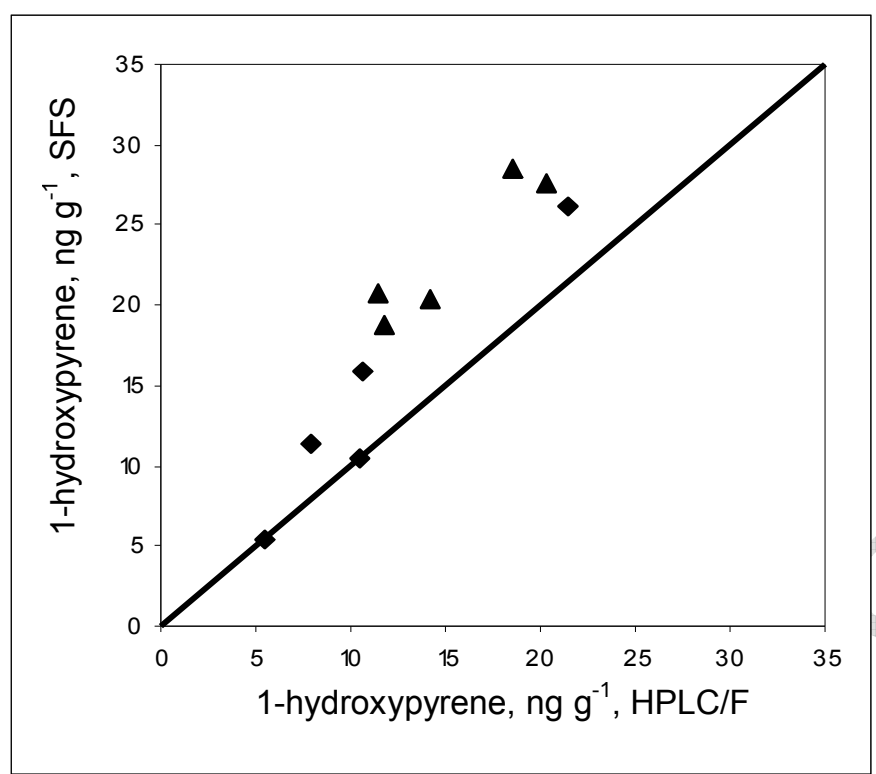

Fig.4.

Correlation of 1-hydroxypyrene concentrations measured by HPLC/F and SFS, in enzymatically hydrolyzed tissue samples ( $\mathrm{ng} \mathrm{g}^{-1}$ ww) from worms exposed to pyrene $\left(-10 \mathrm{mg} \mathrm{kg}^{-1} \mathrm{dw}\right.$; $\mathbf{\Lambda}-30 \mathrm{mg} \mathrm{kg}^{-1}$ $\mathrm{dw})$. The straight line indicates 1:1 ratio. 


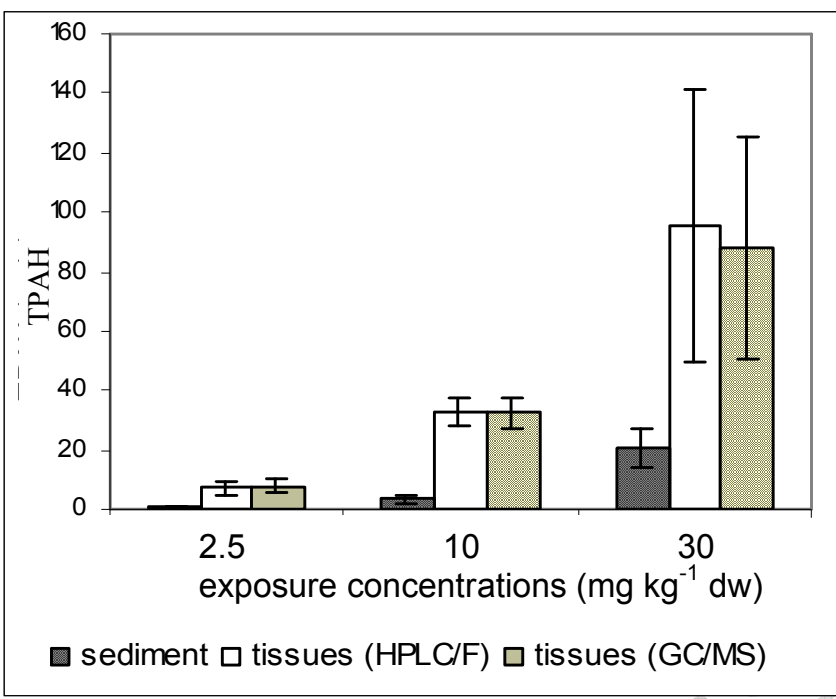

Fig.5.

Total PAH content (TPAH) in sediment (ug g ${ }^{-1} \mathrm{ww}$ ) and animal tissues (ug g $\mathrm{g}^{-1} \mathrm{ww}$ ), from the five PAH exposure experiment. PAH content in tissues was measured by both HPLC/F and GC/MS; in sediment by GC/MS. 


\section{ACCEPTED MANUSCRIPT}

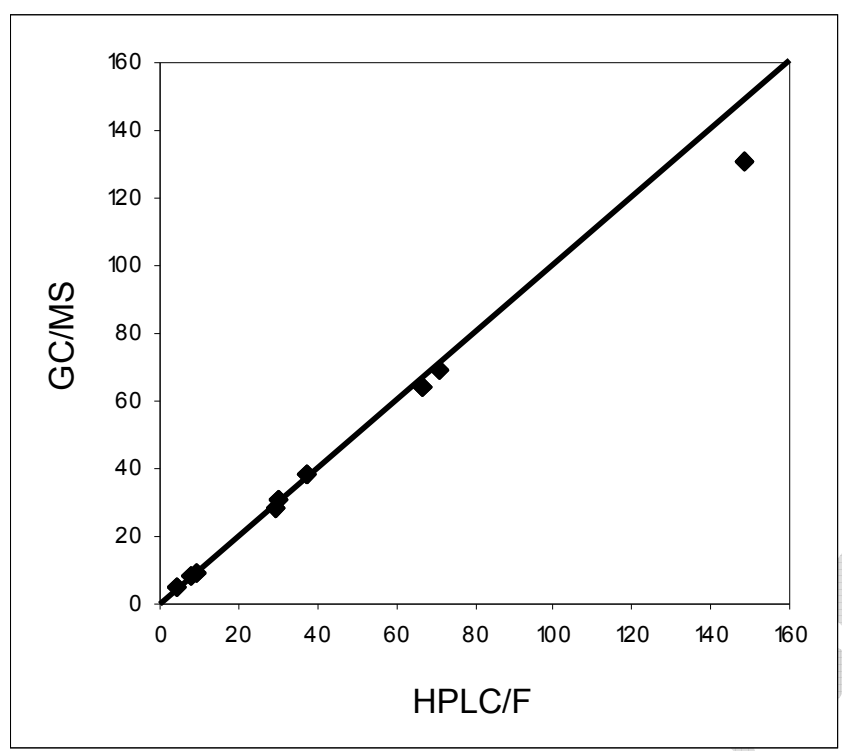

Fig. 6.

Correlation of TPAH values in tissues ( $\mathrm{ug} \mathrm{g}^{-1} \mathrm{ww}$ ), measured by two analytical methods HPLC/F and GCMS. The straight line indicates 1:1 ratio. 
Fig. 7.

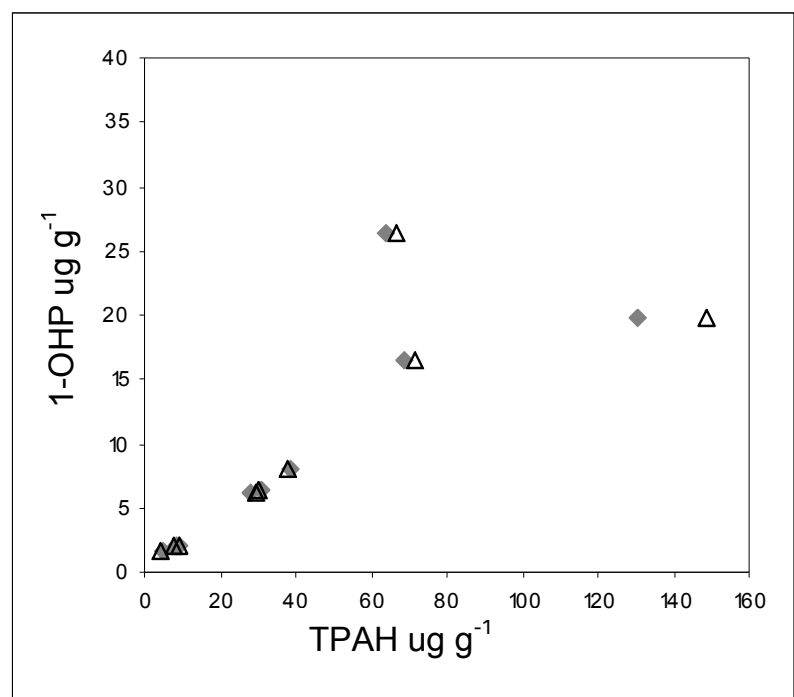

Correlation between 1-hydroxypyrene (1-OHP) concentrations and total PAH (TPAH) concentrations measured by HPLC/F (open symbols) and GC/MS (filled symbols) in the tissues of the exposed worms. 
Fig. 8.

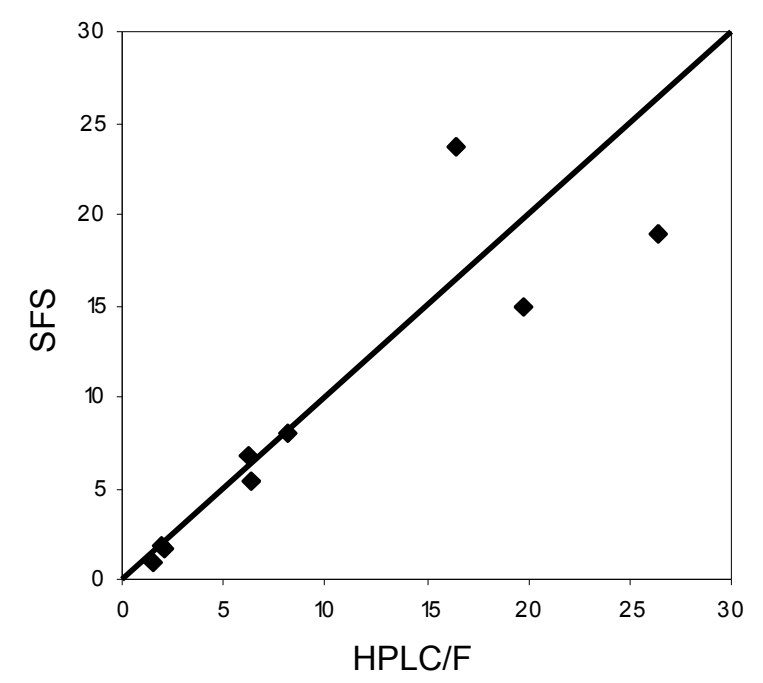

Correlation between 1-hydroxypyrene (1-OHP) concentrations ( $\mu \mathrm{g} \mathrm{g}^{-1}$ tissue) measured by SFS and HPLC/F. The straight line indicates a 1:1 ratio. 


\section{Tables}

\begin{tabular}{ccc}
\hline Correlation & $\mathbf{r}_{\text {s value }}$ & $\boldsymbol{P}$ value \\
\hline 1-OHP (HPLC/F) vs. TPAH (HPLC/F) & 0.950 & $P<0.01$ \\
\hline 1-OHP (GC/MS) vs. TPAH (GC/MS) & 0.950 & $P<0.01$ \\
\hline HPLC/F vs. SFS (1-OHP) & 0.917 & $P<0.01$ \\
\hline HPLC/F vs. GC/MS (TPAH) & 1 & $P<0.01$ \\
\hline
\end{tabular}

Table 1. Results of correlation analysis of 1-hydroxypyrene (1-OHP) and Total PAH (TPAH) content of animal tissues, measured by three analytical methods (HPLC/F, SFS and GC/MS). $\mathbf{r}_{\mathbf{s}}$ and $\boldsymbol{P}$ values identified by Spearman's rank-order correlation $(n=9)$. 